\title{
Recurrent and Metastatic Head and Neck Cancer: A Paradigm Shift?
}

\section{Cancro da Cabeça e Pescoço Recorrente / Metastático: Mudança de Paradigma?}

Leonor Abreu Ribeiro ${ }^{1}$ Cecília Melo-Alvim², Helena Luna Pais², Luís Costa

\section{ABSTRACT}

Head and neck squamous cell carcinoma (HNSCC), the most prevalent pathological subtype of head and neck carcinoma (HNC), can be potentially cured if diagnosed at early stages and adequately treated.

Still, most patients are diagnosed at stages III or IV disease, with estimated local and distant failure rates of $60 \%$ and 30\%, respectively, notwithstanding aggressive multimodality curative intent treatment strategies approved.

The excellent results of the EXTREME trial published in 2008 showing a median overall survival (mOS), of 10.1 months for patients with recurrent and/or metastatic (R/M) HNSCC, treated with platinum plus fluorouracil (5FU) and cetuximab, changed the standard of care (SOC), for these patients. The EXTREME regime was the first to evidence an overall survival (OS) benefit before the immunotherapy era, in this context.

Two immunotherapy drugs are currently approved for treatment of R/M HNSCC in first or subsequent lines of treatment both for platinum-resistant and platinum sensitive disease: the anti-PD-1 agents nivolumab and pembrolizumab.

But does this mean that there is no longer a place for the EXTREME regimen or for chemotherapy in general in R/M HNSCC treatment? And if there is, how to choose between available therapeutic options?

In this article, the authors will address these questions by analyzing data from the main trials that investigated nivolumab and pembrolizumab in this setting.

KEYWORDS: Head and Neck Neoplasms/tratamento farmacológico; Neoplasm Recurrence, Local; Nivolumab; Pembrolizumab

\footnotetext{
1. Consultora de Oncologia Médica, Serviço de Oncologia Médica, CHULN/HSM; Hospital CUF Infante Santo, Cluster Tejo, Instituto CUF Oncologia, Lisboa, Portugal. 2. Interna de formação especifica em Oncologia Médica, Serviço de Oncologia Médica, CHULN/HSM, Lisboa, Portugal.3. Professor Doutor de Oncologia Médica, Diretor do Departamento de Oncologia Médica, CHULN/HSM, Faculdade de Medicina de Lisboa, Instituto de Medicina Molecular, Lisboa, Portugal. 


\section{RESUMO}

O carcinoma pavimento celular (CPC), da cabeça e pescoço, o tipo histológico mais frequente do cancro da cabeça e pescoço, pode ser potencialmente curado se diagnosticado em estadios precoces e tratado adequadamente.

Ainda assim, a maioria dos doentes são diagnosticados em estadio III ou IV da doença, com taxas de falência de resposta ao tratamento, local e à distância, de 60\% e 30\%, respetivamente, apesar de estratégias de tratamento multimodal com intenção curativa.

Os excelentes resultados do ensaio EXTREME, publicado em 2008, com uma mediana de sobrevivência global de 10,1 meses dos doentes com CPC da cabeça e pescoço recorrente elou metastático tratados com platino associado a fluorouracilo e cetuximab, veio alterar o tratamento standard destes doentes. O regime EXTREME foi o primeiro esquema de tratamento a evidenciar um benefício em termos de sobrevivência global, antes da imunoterapia, neste contexto da doença.

Os dois medicamentos de imunoterapia atualmente aprovados para o tratamento do CPC da cabeça e pescoço, em primeira ou subsequentes linhas de tratamento, para doença platino resistente e platino sensível são os agentes anti-PD-L1 nivolumab e pembrolizumab.

Mas será que já não haverá lugar para o esquema EXTREME ou para a quimioterapia em geral para estes doentes? E se há, como escolher entre as opções terapêuticas existentes?

Neste artigo, os autores irão, através da análise dos dados obtidos nos principais ensaios que investigaram o nivolumab e o pembrolizumab neste tipo de doentes, tentar responder a estas questões.

PALAVRAS-CHAVE: Neoplasias da Cabeça e Pescoço/tratamento farmacológico; Nivolumab; Pembrolizumab; Recidiva Local de Neoplasia

\section{IMMUNOTHERAPY DATA ON R/M HNSCC}

Head and neck squamous cell carcinoma (HNSCC), can be potentially cured if diagnosed at early stages and adequately treated.

Still, most patients are diagnosed at stages III or IV disease, with estimated local and distant failure rates of $60 \%$ and $30 \%$, respectively, notwithstanding aggressive multimodality curative intent treatment strategies approved. $^{1-3}$

The excellent results of the EXTREME trial published in $2008^{4}$ showing a median overall survival (mOS), of 10.1 months for patients with recurrent and/or metastatic (R/M) HNSCC, treated with platinum plus fluorouracil (5FU) and cetuximab, changed the standard of care (SOC), for these patients. The EXTREME regime was the only to evidence an OS benefit before the immunotherapy era. ${ }^{1,4,5}$

HNSCC is considered an immunogenic tumor, ${ }^{5}$ partly because of its high mutational burden, being a good candidate for immunotherapy, either by immune blockade suppression or immune response stimulation. Increasing research efforts over the last decade have expanded immunotherapy options for HNSCC, bringing them closer to those available for other tumor types, such as malignant melanoma, lung cancer, and kidney cancer.

\section{A. TREATMENT OF PLATINUM-RESISTANT R/M HNSCC}

Nivolumab was the first immunotherapy drug with proven results in a phase III trial of R/M HNSCC. Promising pre-clinical and phase I and II clinical trial results led to the phase III CheckMate 141 (CM 141) trial, ${ }^{6}$ which enrolled 361 patients with R/M HNSCC progressing within 6 months after platinum-based chemotherapy.

CM 141 achieved a median overall survival (mOS) of 7.5 months for nivolumab versus 5.1 months for the control group, with an estimated 1-year survival rate approximately $19 \%$ higher for nivolumab (36.0\% vs $16.6 \%)$. This was relevant, given the historical mOS of less than 6 months for patients with disease progression within 6 months of standard platinum-based therapy (Table 1).

Other favorable outcomes in this trial included progression-free survival (PFS) rate at 6 months (19.7\% vs 9.9\%), overall response rate (ORR) (13.3\% vs 5.8\%), and grade 3 or 4 treatment-related adverse events (13.1\% vs $35.1 \%)$. As previously described in the publication by Kevin J Harrington et al, ' patient-reported quality of life (QoL) also favored nivolumab, with stable QoL regarding physical, role, and social functioning with the anti-PD-1 compared with meaningfully worse with standard therapies.

Results at the 24-month follow-up (FU), were consistent with initial data: nivolumab nearly tripled the estimated 
OS rate (16.9\%) compared with investigator choice (IC) treatment (6.0\%). ${ }^{8}$ The safety profile observed for longterm survivors was also consistent with previous observations.

Although in this trial the OS and progression free survival (PFS) curves began to separate at 3 months, PFS results were worse before that time, fact consistent in the 24 months FU publication. 6,8

The OS benefit was similar regardless of tumor PDL1 expression ( $\geq 1 \%$ or $<1 \%$ ) or human papillomavirus (HPV) status (positive or negative), although a trend was observed towards better outcomes for PD-L1 "expressors" and HPV-positive patients. However, as PDL1 expression and p16 status were not mandatory for screening and stratification in this trial, they were un- known for a large number of patients (86 and 175, respectively), analyzed in the study.

A total of 222 patients (150 in nivolumab and 72 in the standard-treatment arm) had previously received cetuximab, a stratification factor in CM 141 trial. These were probably patients who received the EXTREME protocol first, with the remaining actually in first-line treatment for R/M disease, after early progression following primary curative intent treatment with cisplatin and radiotherapy.

Overall, patients responded to nivolumab regardless of whether they received cetuximab before, but those who did not, responded better. This was also observed in the KEYNOTE 040 (KN 040) trial, which investigated the other immune checkpoint inhibitor pembrolizumab,?

TABLE 1. Characteristics and results of the 2 phase III trials on R/M SCHNC platinum resistant.

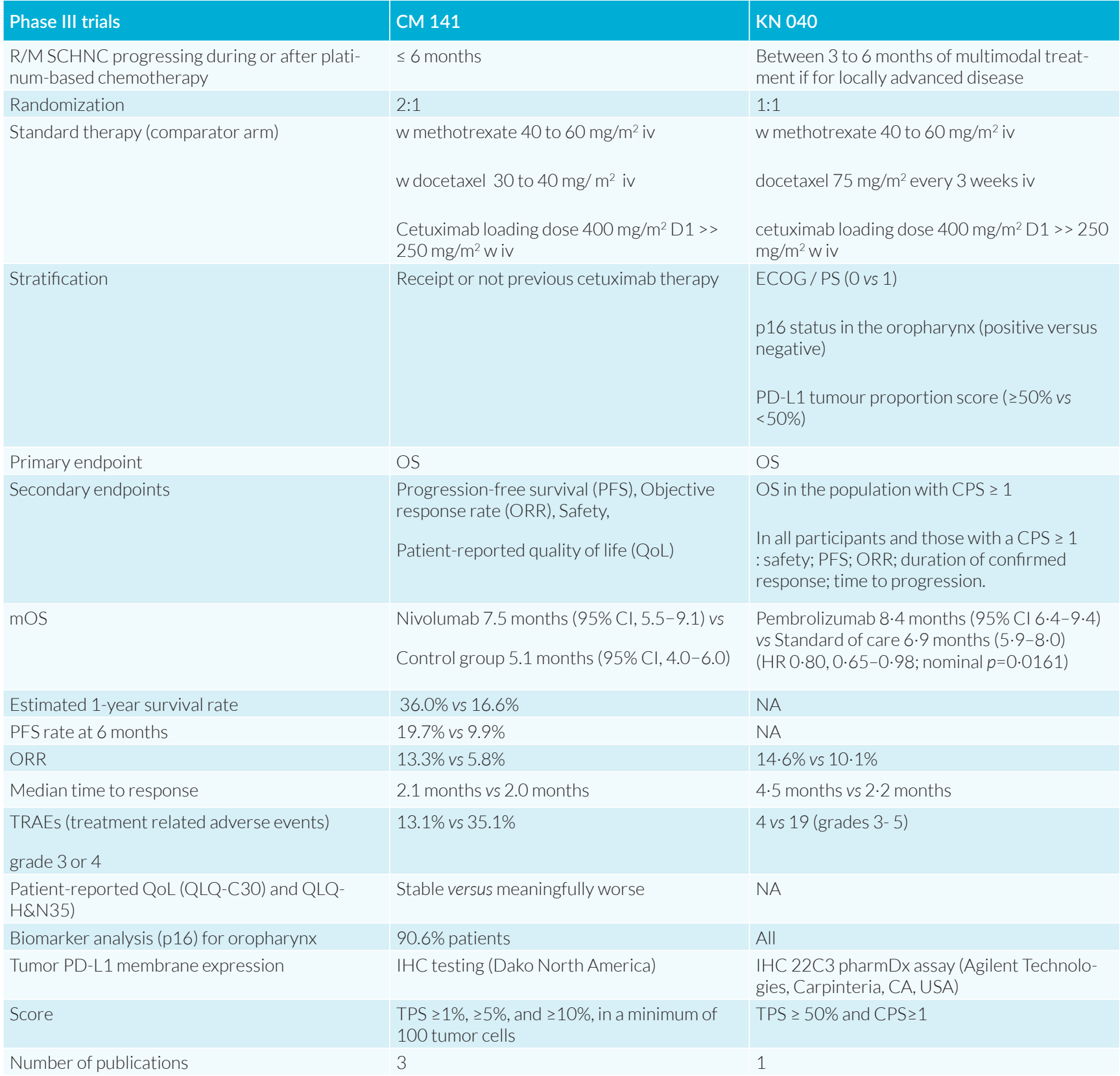


although with a less pronounced difference. This is not surprising for those were patients actually in first line treatment for R/M disease, as mentioned before.

Pembrolizumab (formerly MK-3475 or lambrolizumab) was the other anti-PD-1 to be investigated in R/M HNSCC. The first relevant results with this agent came from the head and neck cohort of the KEYNOTE 012 (KN 012) phase 1b open-label, multicenter trial. This study evaluated the drug's safety and clinical activity in the treatment of R/M HNSCC, with results published in July 2016 in the Lancet Oncology. ${ }^{10}$

KN 012 showed that pembrolizumab was well tolerated and had clinically relevant antitumor activity, leading to the accelerated approval by the Food and Drug Administration (FDA) of the anti-PD-1 for the treatment of R/M HNSCC patients with disease progression after or during platinum-based chemotherapy.

The phase III KN 040 was the confirmatory trial of KN 012. Trial results were presented at the ESMO 2017 Congress and subsequently published in $2018 .{ }^{9}$

KN 040 excluded patients who recurred or progressed within 3 months of previous platinum multimodal therapy for locally advanced disease. By excluding patients with rapidly progressive disease, a better patient selection was achieved, as referred in another publication. ${ }^{11}$

The OS for the group with PD-L1 tumor proportion score (TPS) $\geq 50 \%$ was clearly better for pembrolizumab compared with standard treatment since the first month of treatment, with a hazard ratio (HR) of $0.53(95 \% \mathrm{Cl}$ 0.35-0.81; nominal $p=0.0014)$. Pembrolizumab was also associated with longer PFS in the population with PD-L1 TPS of $50 \%$ (Table 1).

In the KN 040 trial, when disease progressed patients received subsequent therapy, which consisted of immune checkpoint inhibitors in $4 \%$ of pembrolizumab and $13 \%$ of SOC group. In the latter, patients who subsequently received an immune checkpoint inhibitor had a much better mOS than those who received other therapies or even no subsequent therapy (20.1 vs 9.7 vs 4.5 months, respectively).

While no crossover was planned in the KN 040 trial, in CM 141 the protocol was amended to allow patients in the IC arm to crossover to nivolumab arm at the time of disease progression. Another difference between CM 141 and KN 040 was that docetaxel, one of the comparators in standard of care (SOC) arm, chosen in a similar proportion of patients in both trials (approximately 45\%), was used in different doses in each trial: weekly in CM 141 and each 21 days in KN 040. Previous data for various tumors indicate that lower weekly docetaxel doses are better tolerated but have lower efficacy than once-every-3-week doses.

This could also be one subject that makes difficult to compare data from the two trials, even if indirectly. The choice between the two immune checkpoint inhibitors for platinum resistance R/M HNSCC is therefore, difficult to establish if at all in clinical practice. If and when the two drugs are available in each country, the choice will fall in the experience of each clinician for they are both very similar in terms of efficacy and tolerability.

\section{B. TREATMENT OF PLATINUM-SENSITIVE R/M HNSCC}

To our knowledge, KEYNOTE 048 (KN 048) was the only phase III trial to date to investigate the treatment of platinum-sensitive R/M HNSCC. In this trial, pembrolizumab, either in monotherapy or in association with a platinum chemotherapy backbone and 5FU, was compared with the SOC EXTREME protocol. ${ }^{12}$

In KN 048, PD-L1 positivity was not required for study entry, patients were stratified according to PD-L1 expression, p16 status, and performance status and randomized 1:1:1 to pembrolizumab alone, pembrolizumab plus platinum and 5FU, or the EXTREME protocol. Primary endpoints were OS and PFS in the intention-to-treat (ITT) population (Table 2).

Study results showed that pembrolizumab monotherapy improved OS in patients with tumor PD-L1 combined positive score (CPS) $\geq 20$ or $\geq 1$ and had a non-inferior OS compared with SOC in the total study population. Pembrolizumab plus chemotherapy significantly improved OS compared with SOC in patients with tumor PD-L1 CPS $\geq 20$ or $\geq 1$ and in the total study population. Pembrolizumab alone was non-superior to cetuximab plus chemotherapy regarding PFS and objective response. Both endpoints showed similar results for pembrolizumab plus chemotherapy and cetuximab plus chemotherapy.

Compared with the EXTREME protocol, an inferior PFS was observed either with pembrolizumab alone or in combination with chemotherapy in the average first 6 months of treatment, but the median response duration was better with pembrolizumab plus chemotherapy compared with cetuximab plus chemotherapy (7.1 vs 4.2 months in the CPS $\geq 20$ population; 6.7 vs 4.3 months in the CPS $\geq 1$ population; 6.7 vs 4.3 months in the total population).

As expected, compared with the EXTREME regimen the incidence of any-grade or grade $\geq 3$ adverse events was 
TABLE 2. Results of KN 048 for primary endpoints, OS and PFS, at 1st, 2nd interim analysis, and final analysis.

\begin{tabular}{|c|c|c|}
\hline KN 048 & Pembrolizumab versus cetuximab plus CT & Pembrolizumab plus CT versus cetuximab plus CT \\
\hline $\begin{array}{l}\text { OS } \\
\text { CPS } \geq 20 \text { population }\end{array}$ & $\begin{array}{l}14.9 \text { months vs } 10 \cdot 7 \text { months, } \mathrm{HR} 0.61[95 \% \mathrm{Cl} \\
0.45-0 \cdot 83], p=0 \cdot 0007 \text { ) }\end{array}$ & $14 \cdot 7$ vs $11 \cdot 0,0 \cdot 60[0 \cdot 450 \cdot 82], p=0 \cdot 0004)$ \\
\hline $\begin{array}{l}\text { OS } \\
\text { CPS } \geq 1 \text { population }\end{array}$ & $12 \cdot 3$ vs $10 \cdot 30 \cdot 78[0 \cdot 64-0 \cdot 96], p=0 \cdot 0086)$ & $13 \cdot 6$ vs $10 \cdot 4,0 \cdot 65[0 \cdot 53-0 \cdot 80], p<0 \cdot 0001)$ \\
\hline $\begin{array}{l}\text { OS } \\
\text { Total population }\end{array}$ & $11 \cdot 6$ vs $10 \cdot 7,0 \cdot 85[0 \cdot 71-1 \cdot 03]$ & $\begin{array}{l}13.0 \text { months vs } 10.7 \text { months, } \mathrm{HR} 0.77 \text { [95\% Cl 0.63-0.93], } \\
\mathrm{p}=0.0034)\end{array}$ \\
\hline $\begin{array}{l}\text { PFS } \\
\text { CPS } \geq 20 \text { population }\end{array}$ & $(H R 0.99[95 \% \mathrm{Cl} 0.75-1.29], p=0.4562)$ & HR 0.73 [95\% Cl 0.55-0.97], $p=0.0162)$ \\
\hline $\begin{array}{l}\text { PFS } \\
\text { CPS } \geq 1 \text { population }\end{array}$ & HR $1.16[95 \% \mathrm{Cl} 0 \cdot 96-1 \cdot 39]^{* *}$ & $0.82[0 \cdot 67-1 \cdot 00]^{* *}$ \\
\hline $\begin{array}{l}\text { PFS } \\
\text { Total population }\end{array}$ & $1 \cdot 34[1 \cdot 13-1 \cdot 59]^{* *}$ & HR $0.92[95 \% \mathrm{Cl} 0 \cdot 77-1 \cdot 10], p=0 \cdot 1697$ \\
\hline
\end{tabular}

lower with pembrolizumab monotherapy and similar with pembrolizumab plus chemotherapy.

Pembrolizumab alone and pembrolizumab plus chemotherapy were associated with more complete responses and a longer response duration. Pembrolizumab alone improved median response duration by more than 16 months versus cetuximab with chemotherapy. For pembrolizumab monotherapy, greater PD-L1 expression was associated with greater response.

Based on these results, pembrolizumab plus platinum and 5FU was considered a suitable regimen for first-line treatment of R/M HNSCC, and pembrolizumab monotherapy a suitable first-line treatment for PD-L1-positive R/M HNSCC.

The European Medicines Agency (EMA) recommends the use of pembrolizumab as monotherapy or in combination with platinum and 5-fluorouracil (5-FU) chemotherapy, for the first-line treatment of R/M HNSCC in adults whose tumours express PD-L1 with a CPS $\geq 1$, and as monotherapy for the treatment of R/M disease in adults whose tumours express PD-L1 with a $\geq 50 \%$ tumor positive score (TPS) and progressing on or after platinum-containing chemotherapy.

Even so, the authors consider that can still exist a population candidate to the EXTREME protocol. Patients "fit" but symptomatic in the context of a great volume of disease, that need a rapid response and at the same time tolerate the association of platinum, 5FU and cetuximab could probably benefit from this treatment.

Another important aspect is the fact that the skill to determine CPS and TPS need to be acquired from each pa-



FIGURE 1. Sequence of FDA and EMA approvals for clinical practice of Nivolumab and Pembrolizumab.

thology departments to ensure an adequate selection of patients for treatment with pembrolizumab.

The sequence of authorization in the United States of America and in Europe for usage of these two immune checkpoint inhibitors are depicted in Fig. 1.

\section{CONCLUSION}

Keeping in mind that it is not legitimate to compare results of trials with different designs, immunotherapy clearly improves OS in patients with platinum-resistant disease, while preserving QoL. The same is not so straightforward in the platinum-sensitive setting.

It is acknowledged that R/M HNSCC patients who respond to IT have a good response, sustained for a 
longer period of time and with better tolerability than with standard therapies. However, it should be emphasized that some patients may respond worst in the first months of immunotherapy compared with standard therapies and consequently be seriously harmed by it.

Symptomatic patients and those with a high burden of disease requiring a rapid response will probably respond better with chemotherapy upfront. Whether chemotherapy should be combined with cetuximab or pembrolizumab remains unanswered. For example, testing for germline EGFR mutations could potentially help in this selection.

While the clinician must specify to the pathologist the PD-L1 score required to opt for pembrolizumab treatment, no pre-specified PD-L1 score is needed for nivolumab, demanding a tight interaction between specialists.

The human immune system is a complex and fascinating microsystem and its relation with tumor cells is far from total grasp. Consequently, much more needs to be understood to determine the best biomarker(s) for these treatments.

Other immune checkpoints are being tested in early phase clinical trials, for example TIM-3 (T cell immunoglobulin mucin receptor 3), LAG3 (lymphocyte-activation gene 3), TIGIT (T cell immunoreceptor with Ig and ITIM domains), that could bring more information and other means to stimulate and de block our immune system. ${ }^{13}$

Till now there are conflicting data regarding the relation between PD-1, and PD-L1 expression and HPV positivity. Some author refer that higher PD-1 expression in tumor-infiltrating lymphocytes (TILs) of HPV-positive tumours, could mean a strong immune response induced by HPV. Others report differently: high PD-1 levels in HPV-negative HNSCC. Immunosuppressive factors of microenvironment also probably will be important, such as Tregs.

For the time being, only a small proportion of HNSCC patients achieve longer disease control with immunotherapy than with previous therapies. Therefore, it is imperative to better identify patients potentially benefiting from new therapies in order to optimize the overall prognosis of this population.

\section{ACKNOWLEDGEMENTS / AGRADECIMENTOS}

The authors thank Joana Cavaco Silva, PhD in Biomedical Sciences, Scientific Consultant \& Senior Medical Writer for the revision of the English language of the article.

\section{ETHICAL DISCLOSURES}

CONFLICTS OF INTEREST: The authors have no conflicts of interest to declare.

FINANCIAL SUPPORT: This work has not received any contribution grant or scholarship.

PROVENANCE AND PEER REVIEW: Not commissioned; externally peer reviewed.

\section{RESPONSABILIDADES ÉTICAS}

CONFLITOS DE INTERESSE: Os autores declaram não possuir conflitos de interesse.

SUPORTE FINANCEIRO: O presente trabalho não foi suportado por nenhum subsídio ou bolsa.

PROVENIÊNCIA E REVISÃO POR PARES: Não comissionado; revisão externa por pares.

\section{REFERENCES}

1. Sacco AG, Cohen EE. Current treatment options for recurrent or metastatic head and neck squamous cell carcinoma. J Clin Oncol. 2015; 10;33:3305-13. doi: 10.1200/ JCO.2015.62.0963.

2. Argiris A, Kramouzis MV, Raben D, Ferris RL. Head and neck cancer. Lancet. 2008; 17:371:1695-709. doi: 10.1016/ S0140-6736(08)60728-X.

3. Seiwert TY, Cohen EE. State-of-the-art management of locally advanced head and neck cancer. Br J Cancer. 2005; 92:13418. DOI:10.1038/sj.bjc.6602510.

4. Vermorken JB, Mesia R, Rivera F, Remenar E, Kawecki A, Rottey S, et al. Platinum-Based Chemotherapy plus Cetuximab in Head and Neck Cancer. N Engl J Med. 2008; 359:1116-27. doi: 10.1056/NEJMoa0802656.

5. Mandal R, Şenbabaoğlu Y, Desrichard A, Havel JJ, Dalin MG, Riaz N, et al. The head and neck cancer immune landscape and its immunotherapeutic implications. JCI Insight. 2016; 1(:e89829. doi:10.1172/jci.insight.89829.

6. Ferris RL, Blumenschein G Jr, Fayette J, Guigay J, Colevas AD, Licitra L,et al. Nivolumab for recurrent squamous-cell carcinoma of the head and neck. New Engl J Med. 2016; 375: 185667. doi: 10.1056/NEJMoa1602252.

7. Harrington KJ, Ferris RL, Blumenschein G Jr, Colevas AD, Fayette J, Licitra L et al. Nivolumab versus standard, single-agent therapy of investigator's choice in recurrent or metastatic squamous cell carcinoma of the head and neck (CheckMate 141): health-related quality-of-life results from a randomised, phase 3 trial. Lancet Oncol. 2017;18:1104-15. doi: 10.1016/ S1470-2045(17)30421-7. 
8. Ferris RL, Blumenschein G Jr, Fayette J, Guigay J, Colevas AD, Licitra L, et al. Nivolumab vs investigator's choice in recurrent or metastatic squamous cell carcinoma of the head and neck: 2-year long-term survival update of CheckMate 141 with analyses by tumor PD-L1 expression. Oral Oncol. 2018;81:4551. doi: 10.1016/j.oraloncology.2018.04.008.

9. Cohen EW, Soulières D, Le Tourneau C, Dinis J, Licitra L, Ahn MJ, et al; KEYNOTE-040 investigators. Pembrolizumab versus methotrexate, docetaxel, or cetuximab for recurrent or metastatic head-and-neck squamous cell carcinoma (KEYNOTE-040): a randomised, open-label, phase 3 study. Lancet. 2019;393:156-67. doi: 10.1016/S0140-6736(18)31999-8.

10. Mehra R, Seiwert TY, Gupta S, Weiss J, Gluck I, Eder JP, et al. Efficacy and safety of pembrolizumab in recurrent/metastatic head and neck squamous cell carcinoma: pooled analyses after long-term follow-up in KEYNOTE-012. Br J Cancer. 2018;119:153-9. doi: 10.1038/s41416-018-0131-9.

11. Pai SI, Faivre S, Licitra L, Machiels JP, Vermorken JB, Bruzzi P, et al. Comparative analysis of the phase III clinical trials of anti-PD1 monotherapy in head and neck squamous cell carcinoma patients (CheckMate 141 and KEYNOTE 040). J Immunother Cancer . 2019;7:96. doi: 10.1186/s40425-019-0578-0.

12. Burtness B, Harrington KJ, Greil R, Soulières D, Tahara M, de Castro G Jr, et al. Pembrolizumab alone or with chemotherapy versus cetuximab with chemotherapy for recurrent or metastatic squamous cell carcinoma of the head and neck (KEYNOTE-048): a randomised, open-label, phase 3 study. TLancet. 2019;394:1915-28. doi:10.1016/S0140-6736(19)32591-7.

13. Rothschild U, Muller L, Lechner A, Schlösser HA, Beutner $\mathrm{D}$, Läubli $\mathrm{H}$, et al. Immunotherapy in head and neck cancer scientific rationale, current treatment options and future directions. Swiss Med Wkly. 2018; 148:w14625. doi: 10.4414/ smw.2018.14625. 